Geophysical Research Abstracts

Vol. 14, EGU2012-2813-1, 2012

EGU General Assembly 2012

(C) Author(s) 2012

\title{
Cenozoic erosion and flexural isostasy of Scandinavia
}

\author{
B. Gołędowski, D.L. Egholm, O.R. Clausen, and S.B. Nielsen
}

Aarhus University, Department of Geoscience, Aarhus, Denmark (ole.r.clausen@geo.au.dk)

The volume of Cenozoic deposits along the Norwegian Atlantic margin implies significant Cenozoic erosion in a generally cooling climate from the Oligocene to the present. However, except for deep glacial erosion of the fjords, little is known about the distribution of Cenozoic inland erosion. The present day glacial landscape of Scandinavia is different from the fluvial predecessor that must have existed prior to Cenozoic cooling. In addition to the nonfluvial fjords, the present high topography in western Scandinavia displays a series of low relief surfaces in the form of summit flats between the fjords - perhaps reflecting long-term periglacial denudation. In this study we estimate the patterns of Cenozoic erosion by quantifying the topographic difference between the present landscape and a pre-Cenozoic fluvial predecessor. In order to achieve this, we reconstruct the pre-Cenozoic fluvial landscape using a fluvial landscape evolution model including the flexural isostatic response to the transfer of rock mass - from the basins back onto the onshore area. The volume of rock added to the present landscape during the reconstruction is constrained by the present offshore Cenozoic sediment matrix volumes, which has been mapped using 2D seismic data and numerous exploration wells. We find that most of the offshore sediments are needed for filling the fjords created during the Late Neogene glaciations and for restoring concave river profiles from sea level to the peaks. Consequently, the reconstructed fluvial landscape on average is less than 300m higher than today. Some isolated peaks are up to $1000 \mathrm{~m}$ higher than today. Furthermore, the offshore tilting of pre-Cenozoic strata can be explained by flexural isostatic compensation in response to the Cenezoic erosion and deposition. 